\title{
SYNTHESIS OF COMPOSITE POLYMER FOR INDUSTRIAL APPLICATION
}

\author{
Prakash Sutar ${ }^{1}$, D. K. Dond ${ }^{2}$, \\ ${ }^{1}$ Asst Professor ,SIEM,Sandip Foundation, Nashik, Maharashtra State, India \\ ${ }^{2}$ Asst Professor, MET's Bhujabal Knowledge City C.O.E, Nashik, Maharashtra State, India
}

\begin{abstract}
The Method of Fused Deposition Modelling is most popular rapid prototyping process producing parts layer by layer which is mainly made up of polymer. But the use of these parts is restricted because of low strength of plastic. To achieve efficient mechanical properties, metal composite polymer can be used which has not been used as feedstock material in FDM. Plastic component are most commonly produced by injection molding process. Wide variety of shapes and sizes of thin walled plastic parts are manufactured by this method. The aim of present study was to fabricate new metal composite and to investigate the effect of addition of metal powder on strength of polymer. As both FDM and Injection moulding are similar process the feasibility of metal composite feedstock was checked in injection moulding process. Experiments were carried out on parts produces by injection moulding process with different composition of metal and polymer. Six specimens with different proportions of aluminum and copper in polymer by weight were prepared as per the ASTM standard for Tensile and Flexural test. It can be concluded that addition of copper increases tensile strength of parts and aluminum increases bending strength of parts produced by Injection Moulding process.
\end{abstract}

Key Words: Rapid Prototyping, Metal Composite polymer, Injection Moulding, $* * *$

\section{INTRODUCTION}

Stratasys in Eden Prairie, Minnesota has developed the process of Fused Deposition Modelling (FDM). The process uses plastic or wax material as build material and which is extruded through a nozzle which traces cross sectional geometry of part layer by layer. Usually the build material in the form of filament is supplied but some setups also use material in form of plastic pellets which is fed from hopper. The plastic is maintained at temperature just above its melting point with the help of resistive heaters in nozzle so that it can flow through nozzle easily and forms layer. After flowing through nozzle the plastic hardens and bonds to the layer below. Whereas in the process of Injection Moulding the material is first melted in injection chamber and then injected into the mould, where the melted material cools down and finished part is ejected. This process also incorporates material in form of pellets fed from hopper into the chamber. The forward movement of material in chamber is done with the help of "Piston and cylinder" arrangement. In injection chamber the plastic is heated with the help of heating elements. The injection chamber is maintained at specific temperature with the help of cooling system. This molten plastic is injected into the required mould cavity through nozzle where this moulded parts get cooled quickly in the mould. The final plastic parts is obtained from the mould afterwards.

The variety of material can be processed with injection moulding process such as Polyamide (Nylon), Polyetherimide, Acrylic, Acrylonitrile Butadiene Styrene (ABS), Acetal, Polyester, Cellulose Acetate, Polycarbonate, Polyether Sulphone (PS), Polyphenylene Sulphide (PPS), Polypropelene (PP), Polyetherketone (PEEK),polyethylene Oxide, Polyvinyl Chloride (PVC) and Elastomer. The problem with the products produced by Fused deposition modeling is that materials it uses is restrained in application because it is mainly plastic, which is having less strength. The composite matrix polymer can be solution to this problem. As injection moulding process is similar to Fused Deposition Modelling process so same material can be suggested for FDM also. So aim of present study was to check suitability of metal matrix polymer material as raw material in injection moulding process. Following was the literature reviewed related to the research on composite material.

\subsection{Literature Survey}

Zhong et al. (2000) the critical issues related to material property of short fiber reinforced composite was addressed and they concluded that by adding short glass fiber as reinforcement in ABS improves parameters like surface rigidity, heat distortion temperature and softening 
temperature but surface toughness was decreased. To avoid this plasticizer was used (LLDPE at different grade i.e. 7042 and 0209) to improve ductility and flexibility and test it at different $\%$ proportion. But to avoid incompatibility at $30 \%$ of LLDPE a compatibilizer (hydrogenated Buna -N) were added and final short fibre composite material formed to suite FDM machine. Kalita et al (2003) developed method of fabrication of controlled porosity polymer-ceramic composite scaffold for improving supply of blood, nutrient and Oxygen for better growth of bones. Particulate reinforced Polymer ceramic composite polypropylene (PP) Polymer and tricalcium phosphate (TPC) ceramic was developed for this purpose. After this the tensile test were conducted on the pure polypropylene polymer, PP with addition of wax and plasticizer and PP with wax and plasticizer with TPC(tricalcium phosphate ceramic) and after this the uniaxial compression test were conducted on PP-TPC composite structure with different $\%$ of volume. After they conclude that with best result of compressive strength up to $12.7 \mathrm{MPa}$ was obtained under pore size of 160 $\mu \mathrm{m}$ and volume of $36 \%$ while PP-TPC with wax and plasticizer give poor result in tensile tastings. Masood and Song (2004) studied over the new polymer material for fused deposition modelling in which they used iron/nylon mixture within which P301 nylon matrix is used with different $\%$ (by volume) of both in different iron particle sizes like $50-80 \mu \mathrm{m}$ and less than $30 \mu \mathrm{m}$. This enhance the strength, toughness and conductivity than existing polymer, but to due to loading of iron powder the viscosity of the mixture increase which result in buckling at entrance of liquefier and to avoid this small amount of surfactant and plasticizer were used. And then the tensile test was perform on the three specimen with different $\%$ of iron and nylon using Intron testing machine to conclude that with 40/60\% of iron/nylon suite to FDM machine without any modification and mixture produce better inserts than the inserts produced by SLA process as it reduce the cycle time and the injection pressure in FDM. Jelena et al. (2007) explore the use of rapid prototyping in medical application. In this CT scanner or MRI data can be used as the modelling data as it gives the 3-D image data. Using this one can proceed further for surgical planning, training, modelling in tissue engg., biomechanics and approach towards critical operations and much more in medical field. Kurt et al. (2007) in the field of FDM, modify the FDM 1600liquifier subsystem to accommodate the reduced column strength of the soft thermoplastic elastomer(STPE) filament stock with hardness 72 and 78 shore referred as STPE1 and STPE2. These two satisfy the melt process ability and ability to flow with only the addition of heat which is the material requirement for STPE to fabricate custom fit aircrew oxygen masks(CFAOMs) required by U.S. Air force. But he concluded that the modification is require with STPE1 and
STPE 2 was the easier one among two of them to work with. Nagarjan et al. (2009) studied application and the steps involving rapid prototyping in detail in medical field. In this the step like data acquisition, image processing and model production are include for modelling and part production in RP. As well as the different phases in which the rapid prototyping is used like biomedical engineering for complex surgery planning and operations and design and manufacturing of biocompatible and bioactive implant as well as tissue engineering. Nikzad et al. (2009) studied two dimensional and three dimensional flow of ABS-iron composite material in FDM through the liquefier head which is the 900 (liquefier model used in FDM 3000) bent tubes to analyze the melt flow behavior. ANSYS FLOTRON and CFX finite element packages with parameters like temperature, velocity and pressure drop was tested for this purpose. In this composite material $10 \%$ of iron and $5 \%$ of surfactant material used and experiments are done to characterize the rheological, thermal and mechanical properties.

\section{MATERIAL AND METHODS}

To study the effect of metal composite material on mechanical properties, six different composition of main material and the metallic powder in $\%$ by weight. In this the surfactant material is used to improve the covalent bonding and the flow ability between the ABS and the metallic powder. Standard test specimens were modelled as per the ASTM standard using CATIA software. The standards are ASTM D638 specimen for tensile test and ASTM D790 specimen for a flexural test. Tensile test specimen has dimensions $63 \mathrm{~mm} \times 9.53 \mathrm{~mm} \times 3.5 \mathrm{~mm}$ with cross section width $9.53 \mathrm{~mm}$ with radius of $12.7 \mathrm{~mm}$ and flexural test specimen having dimensions 127 x $13 \times 3.5 \mathrm{~mm}$.

Copper powder and aluminum powder was used as reinforcement material in this study. Copper powder and aluminum powder was obtained from the open market with particle size of about $50 \mu \mathrm{m}$.

Table- 1: Composition of polymer composites

\begin{tabular}{|l|c|c|c|}
\hline Composition & $\begin{array}{c}\text { ABS } \\
\text { (matirx } \\
\text { material) }\end{array}$ & $\begin{array}{c}\text { Metallic } \\
\text { Powder } \\
\text { (reinforcing } \\
\text { particle) }\end{array}$ & $\begin{array}{c}\text { Noninphinoethoxylate } \\
\text { (Surfactant material) }\end{array}$ \\
\hline Composition1 & $65 \%$ & $30 \%(\mathrm{Cu})$ & $5 \%$ \\
\hline Composition2 & $44 \%$ & $50 \%(\mathrm{Cu})$ & $6 \%$ \\
\hline Composition 3 & $23 \%$ & $70 \%(\mathrm{Cu})$ & $5 \%$ \\
\hline Composition 4 & $65 \%$ & $30 \%(\mathrm{Al})$ & $6 \%$ \\
\hline Composition 5 & $44 \%$ & $50 \%(\mathrm{Al})$ & $7 \%$ \\
\hline Composition 6 & $23 \%$ & $70 \%(\mathrm{Al})$ & \\
\hline
\end{tabular}


It is required to have different composition of same material to get the best result in mechanical properties with respect to strength of same composite material. For this \% by weight of each main material (ABS), metallic powder (copper and aluminum $99.9 \%$ pure) and surfactant (noninphinoethoxylate) material is used. The compositions are shown in table1. In the percent by weight of the copper should be maintain at least with the difference of the $20 \%$ get the accurate and best result in the moulding and enhancing mechanical properties of composite material.

The material takes the inverse shape of the mould in which it is injected through the hot barrel in injection moulding. It is possible to have the multiple cavity mould rather than the single cavity mould for time saving production. It is possible that the multiple cavity mould having different geometry regarding with same standard or same geometry in multiple numbers to take the advantage of the single stroke cycle. Steel are generally used to make mould, but aluminum and the stainless steels are the preferable one for most of the application. In moulding of the specimens of the given ASTM standard we used multiple cavities mould made up of stainless steel to save time as well as the raw material as shown in figure 1 and the vertical hand operated injection moulding machine in figure 2 .
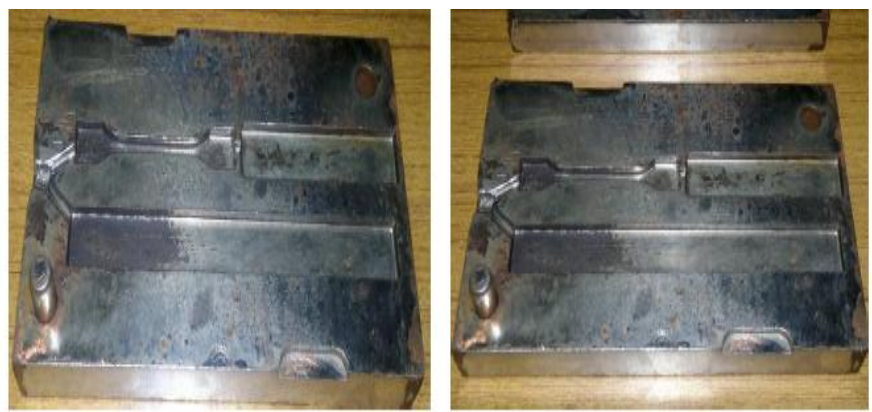

Fig -1: Stainless steel mould

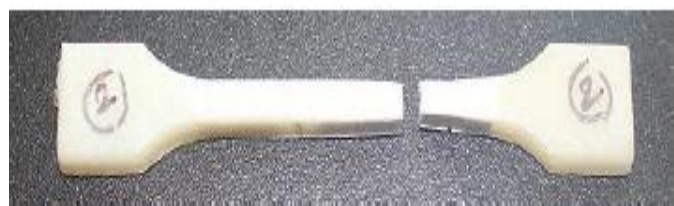

Fig -3 a): Plain ABS specimen made by Injection moulding after tensile test.

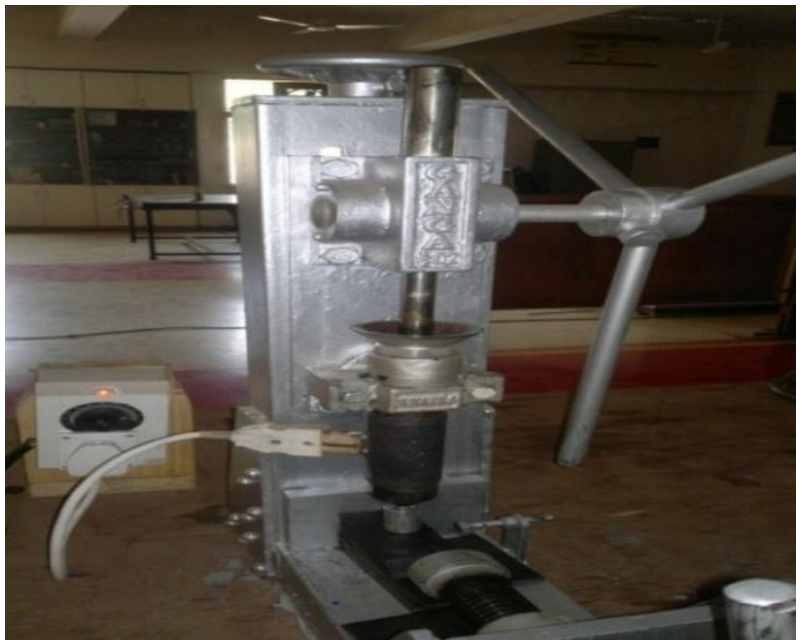

Fig -2: Injection moulding machine

\section{RESULTS AND DISCUSSIONS}

\subsection{Tensile Test Result}

Tensile test results for plain and for six compositions parts fabricated by injection moulding process is shown in Table 2. Plain ABS tensile strength is more than the copper and aluminium reinforced metallic powder. Also the copper tensile strength is more than the aluminium polymer composites. As the copper composition increases the tensile strength increases. Figure $3 \mathrm{a}$ ), b) and c) shows the test specimens after tensile test.

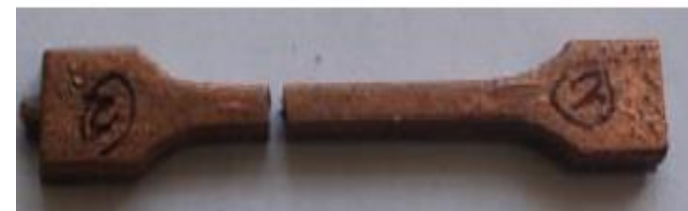

Fig -3b): $\mathrm{ABS}+\mathrm{Cu}$ Specimen made by Injection Moulding after tensile test.

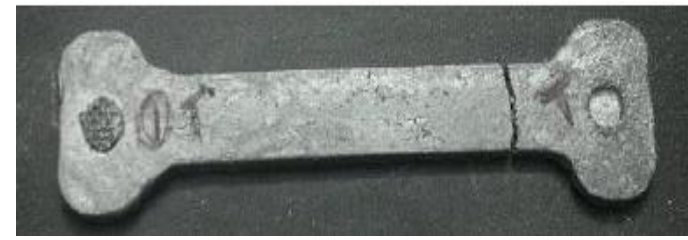

Fig.-3c) : $\mathrm{ABS}+\mathrm{Al}$ injection moulded specimen after tensile test

Table -2: Tensile test results of plain ABS and composites for injection moulded parts.

\begin{tabular}{|c|c|c|c|c|c|c|c|}
\hline $\begin{array}{c}\text { No of } \\
\text { Test }\end{array}$ & $\begin{array}{c}\text { Plain ABS } \\
(\mathrm{MPa})\end{array}$ & $\begin{array}{c}\text { Composition 1 } \\
(\mathrm{MPa})\end{array}$ & $\begin{array}{c}\text { Composition 2 } \\
(\mathrm{MPa})\end{array}$ & $\begin{array}{c}\text { Composition 3 } \\
(\mathrm{MPa})\end{array}$ & $\begin{array}{c}\text { Composition 4 } \\
(\mathrm{MPa})\end{array}$ & $\begin{array}{c}\text { Composition 5 } \\
(\mathrm{MPa})\end{array}$ & $\begin{array}{c}\text { Composition 6 } \\
(\mathrm{MPa})\end{array}$ \\
\hline 1 & 43.95 & 32.339 & 37.995 & 37.995 & 25.28 & 10.8 & 10.49 \\
\hline 2 & 42.53 & 35.714 & 37.774 & 37.616 & 19.644 & 24.25 & 12.88 \\
\hline 3 & 46.31 & 41.057 & 36.6 & 38.48 & 27.74 & 12.17 & 13.21 \\
\hline Avg & 44.26 & 36.37 & 36.66 & 38.02 & 24.22 & 15.74 & 12.19 \\
\hline
\end{tabular}




\subsection{Bending Test Results}

Three point bending test was carried out which gives the result about the flexural strength when the material is subjected to simple beam loading. It is the strength up to which the specimen can sustain under maximum stress. In case of bending test the load is applied till approximate deflection of $7.8 \mathrm{~mm}$ is seen and load respective to maximum stress is noted down.

Table- 3: Result of Bending Test for Plain ABS and Composites made by Injection Moulding.

\begin{tabular}{|l|l|l|l|l|l|l|l|}
\hline $\begin{array}{c}\text { No of } \\
\text { Test }\end{array}$ & $\begin{array}{c}\text { Plain ABS } \\
(\mathrm{MPa})\end{array}$ & $\begin{array}{c}\text { Composition 1 } \\
(\mathrm{MPa})\end{array}$ & $\begin{array}{c}\text { Composition 2 } \\
(\mathrm{MPa})\end{array}$ & $\begin{array}{c}\text { Composition 3 } \\
(\mathrm{MPa})\end{array}$ & $\begin{array}{c}\text { Composition 4 } \\
(\mathrm{MPa})\end{array}$ & $\begin{array}{c}\text { Composition 5 } \\
(\mathrm{MPa})\end{array}$ & $\begin{array}{c}\text { Composition 6 } \\
(\mathrm{MPa})\end{array}$ \\
\hline 1 & 53.864 & 45.252 & 48.87 & 32.042 & 55.06 & 55.43 & 28.19 \\
\hline 2 & 54.89 & 42.157 & 27.842 & 46.51 & 56.17 & 43.55 & 21.42 \\
\hline 3 & 53.284 & 46.317 & 28.332 & 43.41 & 62.62 & 53.73 & 33.32 \\
\hline Avg & 54 & 44.575 & 34.67 & 40.65 & 57.84 & 50.39 & 27.81 \\
\hline
\end{tabular}

Table 3 shows the bending test results for plain and for six compositions parts fabricated by injection moulding process. Plain ABS tensile strength is more than the copper and aluminium reinforced metallic powder. Also the aluminium polymer composites tensile strength is more than the copper polymer composites. Figure 4 a), b) and c) shows the test specimens after bending test.

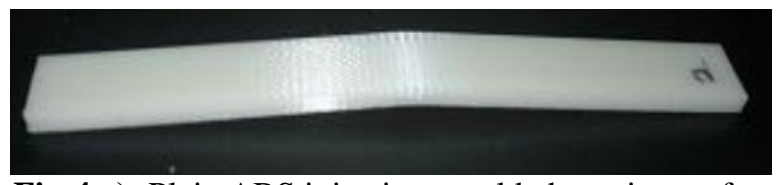

Fig-4.a): Plain ABS injection moulded specimen after bending test

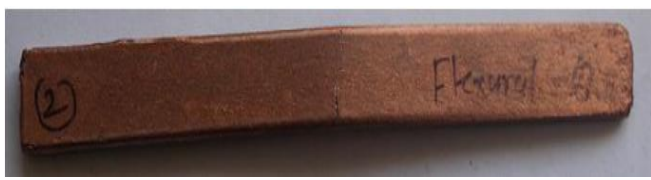

Fig-4 b) :ABS + Cu injection moulded specimen after bending test

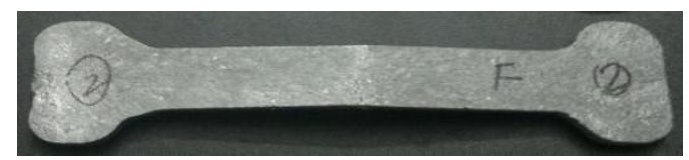

Fig-4 c): $\mathrm{ABS}+\mathrm{Al}$ injection moulded specimen after bending test

\section{CONCLUSIONS}

Test specimens were fabricated successfully on vertical hand operated injection moulding machine using six different compositions. The Compositions '1', '2' and ' 3 ' were prepared with varying proportion of ABS, pure copper and surfactant material. And the compositions '4', '5' and '6' were prepared with varying proportion of $\mathrm{ABS}$, pure aluminium and surfactant material. It was observed that as the percentage of the copper in the composite material increased the tensile strength of the specimen's increases. In case of the flexural tests it was observed that composition 1 has higher strength than composition 2 and 3. Copper filled ABS composite showed good mechanical properties in comparison of aluminum filled ABS composite. As the different mechanical tests were performed on specimens having different composition, the pure ABS specimen were fabricated using injection moulding process and tensile and flexural test were performed on three specimen to get the accurate result and to validate this. Specimen fabricated from injection moulding process showed the maximum result with tensile strength of $46.31 \mathrm{MPa}$ and flexural strength of $54.89 \mathrm{MPa}$. In case of fused deposition modelling the tensile strength of $35.45 \mathrm{MPa}$ and flexural strength of $45.20 \mathrm{MPa}$ was obtained. From these result it can be concluded that the injection moulded parts possess the higher mechanical properties than the fused deposition modelling parts.So use of metal polymer in FDM can be done as feedstock material.

\section{REFERENCES}

[1]. Weihong Z., Zuoguang Z., Lulu S., Fan L., Zhimin L.; Short fibre reinforced composite for fused deposition modelling, Materials Science and Engineering .A301,125-130,2000

[2]. Kalita S., Bose S., Hosik H., Bandyopadhyay A.; Development of controlled porosity polymer ceramic composite scaffolds via fused deposition modelling, Materials Science and Engineering. C(23),611620,2003.

[3]. Masood S, Song W.; Development of metal/polymer material for rapid prototyping using fused deposition modeling, Materials and Design.25, 587-594, 2004.

[4]. Nagarjun T., Shilinge G., Syed A., Badani S.; Rapid prototyping techniques in medical field, Research J. Pharm. and Tech.1(4), 341-344, 2009.

[5]. Milovanovic J, Trajanovic M; Medical application of rapid prototyping, Mechanical engineering.5, 79-85, 2007.

[6]. Kurt E., Howard N., Ja1nak C.; Soft elastomer for fused deposition modelling, Virginia polytechnic Institute and state university, 441-448, 2007

[7]. Mostan N., Syed M., Igor S., Andrew G.; A Study of Melt Flow Analysis of an ABS Iron Composite in Fused Deposition Modelling Process, TSINGHUA SCIENCE AND TECHNOLOGY.05/38 /S1/14, 29-37, June 2009.

[8]. Mostan N., Syed M., Igor S., Andrew G. (2009), A Study of Melt Flow Analysis of an ABS-Iron 
Composite in Fused Deposition Modelling Process, TSINGHUA SCIENCE AND TECHNOLOGY.05/38 /S1/14, 29-37.

[9]. Agnes B., Volkar S. (2011), Mechanical properties of fused deposition modelling parts manufactured with UTLEM*9085, Direct manufacturing research centre ANTEC.

[10]. Novakova L., Novak J. (2012), Testing of materials for rapid prototyping fused deposition modelling technology, World academy of science, engineering and technology 70,411-414.

[11]. Dani T., Kamdi P., Nalamwar G., Borse V. (2013), Multi objective optimization of built orientation for rapid prototyping of connecting rod, International Journal of Scientific research and Management.1(1), 13-18.

Nagarjun T., Shilinge G., Syed A., Badani S.; Rapid prototyping techniques in medical field, Research J. Pharm. and Tech.1(4), 341-344, 2009.

\section{BIOGRAPHIES}

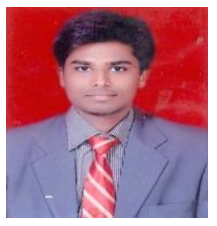

I am P. M.Sutar Working as asst professor in Sandip foundation from last three years also perusing masters of Engineering in CAD CAM \& Engg stream from MET $\mathrm{BKC}$ COE. 